\title{
Unmanned Aerial Vehicles in Agriculture: A Survey
}

\author{
Jaime del Cerro* $*$, Christyan Cruz Ulloa, Antonio Barrientos $(\mathbb{D}$ and Jorge de León Rivas
}

Centre for Automation and Robotics (CAR) Universidad Politécnica de Madrid—Consejo Superior de Investigaciones Científicas, 28006 Madrid, Spain; christyan.cruz@car.upm-csic.es (C.C.U.); antonio.barrientos@upm.es (A.B.); jorge.deleon@upm.es (J.d.L.R.)

* Correspondence: j.cerro@upm.es

\section{check for} updates

Citation: del Cerro, J.; Cruz Ulloa, C.; Barrientos, A.; de León Rivas, J. Unmanned Aerial Vehicles in Agriculture: A Survey. Agronomy 2021, 11, 203. https://doi.org/ 10.3390/agronomy11020203

Received: 8 December 2020

Accepted: 18 January 2021

Published: 21 January 2021

Publisher's Note: MDPI stays neutral with regard to jurisdictional claims in published maps and institutional affiliations.

Copyright: (c) 2021 by the authors. Licensee MDPI, Basel, Switzerland. This article is an open access article distributed under the terms and conditions of the Creative Commons Attribution (CC BY) license (https:// creativecommons.org/licenses/by/ $4.0 /)$.

\begin{abstract}
The number of tasks that nowadays are accomplished by using unmanned aerial vehicles is rising across many civil applications, including agriculture. Thus, this work aims at providing the reader with an overview of the agronomical use of unmanned aerial vehicles. The work starts with a historical analysis of the use of aircrafts in agriculture, as pioneers of their use in modern precision agriculture techniques, currently applied by a high number of users. This survey has been carried out by providing a classification of the vehicles according to their typology and main sensorial and performance features. An extensive review of the most common applications and the advantages of using unmanned aerial vehicles is the core of the work. Finally, a brief summary of the key points of the legislation applicable to civil drones that could affect to agricultural applications is analyzed.
\end{abstract}

Keywords: RPAS; autonomous aerial vehicles; precision agriculture

\section{Introduction}

According to the Association for Unmanned Vehicle Systems International AUVSI [1], there are more than 2900 Unmanned Aerial Vehicles (UAV) across more than nine hundred companies providing services around the world in 2020.

Not only drone manufacturers, but also Unmanned Aerial System (UAS) providers, which incorporate application-oriented elements to the UAVs are developing custommade solutions to effectively handle the needs of the end users. Thus, advances in UAV technologies have made it possible for the companies to produce a wide range of models in different sizes, weights and shapes, capable of carrying different sensor payloads.

A recent analysis and forecast report [2] carried out in the USA by using data from the period of 2014 to 2017 states that the main applications areas in the use of UAV are filming and photography, inspection and maintenance, mapping and surveying, surveillance and monitoring and precision agriculture, in addition to other miscellaneous applications. According to the mentioned report, precision agriculture applications are expected to witness considerable growth, since the use of drones is becoming one of the most critical aspects of managing fundamental operations of farms. These devices can help farmers in a wide variety of operations, including analysis and planning of crop plantation as well as field monitoring to determine the growth and health of crops.

Moreover, the USA Federal Aviation Administration (FAA) forecast 2019-2038, provided by AUVSI, reports that agriculture will be in the sixth place considering the number of missions, representing a $7 \%$ of the total after R\&D/Training/Education (21\%), film/event/entertainment/sport (21\%), and industrial/utility/environment/oil/gas (16\%) as the most relevant uses of UAVS.

According to the mentioned forecast, factors such as the increase in UAV venture funding, technological developments and applications in commercial sectors such as 3D mapping and drone delivery, are expected to contribute to market growth. However, several security and safety concerns, lack of trained pilots, and UAS traffic management issues are some of the factors that can affect the growth of the commercial drone market. 
The data provided highlight the relevance of agriculture in the unmanned aerial vehicles market, not only based on current statistics but also in forecast for the coming years, which served as motivation to carry out the following survey.

This work encompasses the complete UAS concept, which is generally used to describe the entire operating equipment, including not only the aircraft and base station, but also the sensors required for the missions.

Accordingly, a review of some historical milestones of the aviation in agriculture and the evolution towards unmanned vehicles is provided in Section 2. Section 3 provides several classifications of the unmanned aerial vehicles and the corresponding analysis of the advantages and drawbacks of each type being used in agriculture.

An analysis of commercial UAS is presented in Section 4, providing key features of the vehicles and sensors commonly used in agriculture. A review of the customization efforts carried out by some drone manufacturers to provide the market with systems specifically oriented to agricultural tasks is also included in this section.

A classification of agricultural missions obtained from a deep analysis of the literature is presented in Section 5. In this section, the missions have been clustered according to their goal and selected examples have been highlighted considering different crops and sensors.

Section 6 summarizes the regulatory frame that applies to UAVs and the restrictions that affect to the most common agricultural applications. Finally, the most relevant conclusions are presented in Section 7.

\section{Historical Background and Trends in Agricultural Aviation}

Multiple unreferenced sources state that the first known aerial application of agricultural materials was in 1906 by John Clervaux Chaytor, who spread seeds over a swamped valley floor in Wairau (New Zealand) on the family farm "marshlands" by using a hot air balloon with mobile tethers. Soon after, in 1921, a plane was used in crop dusting by the US Agriculture Department and the US Army Signal Corps research station in Ohio [3].

The advantages of using aerial services in agriculture favored the extension to other tasks such as top dressing, the application of fertilizers over farmland from the air in 1940.

Nevertheless, physical treatments were not the unique use of aerial vehicles in agriculture. Thus, there are works documented in 1930 and applications since 1950s on the use of infrared aerial photography to detect loss of vigor in wheat and other small grains due to several diseases by using planes [4].

Unlike commercial services that used fix wing solutions for crop dusting, Yamaha developed probably the first Unmanned Aerial Vehicle (UAV) applied to agriculture in 1997 by using a rotary wing aircraft (Figure 1). Using helicopters showed big advantages in field spraying due to their high maneuverability, reduced speed and velocity and the positive impact of the airflow from the rotor in spraying tasks. This was possible thanks to the applications of novel fuzzy control techniques by Professor M. Sugeno for controlling unstable systems such as helicopters [5].

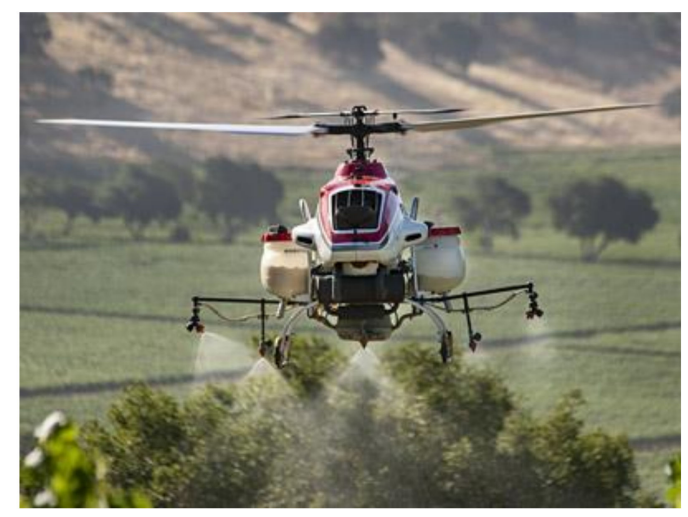

Figure 1. Yamaha RMAX (permission obtained) [6]. 
Since being introduced in 1997, Yamaha RMAX helicopters have flown more than 2 million hours treating 2.4 million acres of farmland in Japan each year (2014). Over 2600 Yamaha helicopters are operating worldwide (2014) [6].

Nevertheless, in the 1990s, multiple countries limited or even banned aerial application of products such as pesticides or fertilizers. Moreover, in 2009 the European Union mostly prohibited aerial spraying of pesticides, which effectively ruined most commercial services of aerial application in all member states and overseas territories.

Conversely, the irruption in the market of aircrafts popularly known as "drones", usually based on inexpensive multi-rotor vehicles, has enabled the growth of affordable applications of UAVs in agriculture, mainly in aerial imaginary and monitoring missions.

Considering a scientific point of view, the use of UAV seems to have a later existence. Thus, by checking the topic UAV in the Web of Knowledge, only few works appear in the 1990s, although the number of works grows exponentially in a few years from 2011 as Figure 2 shows. Extending the search to RPAS (Remotely Piloted Aerial System) increases in a very small number the results obtained.

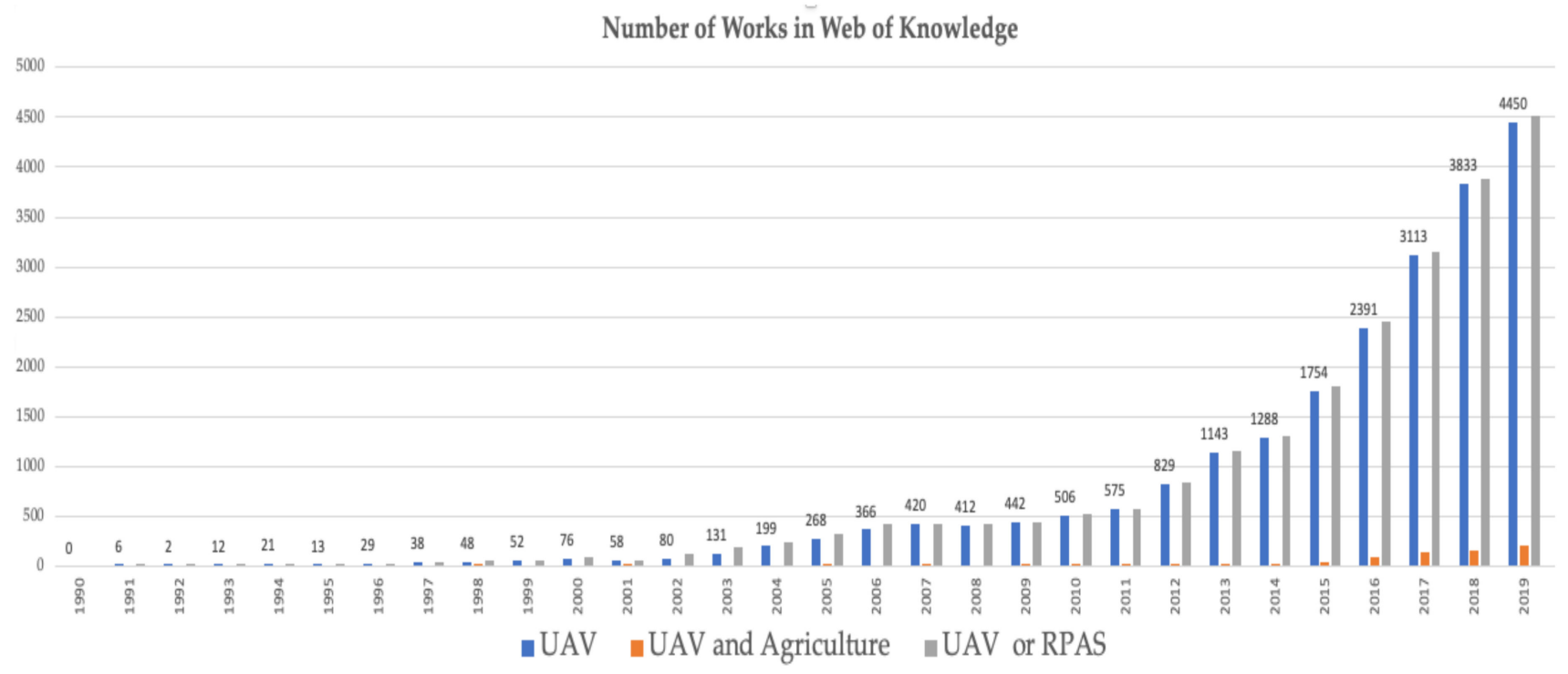

Figure 2. Numbers of works in the Web of Knowledge including UAV or UAV and agriculture as topic.

There is no doubt that the obtained results have been affected by the late appearance of the UAV term, since several works on autonomous helicopters carried out by Gilmore at the Georgia Institute of Technology can be found in 1984 [7]. Thus, the term "autonomous helicopter" was predominant until 2015 when the term "drone" became more usual when referring to unmanned aircrafts.

\section{UAV Classification}

Multiple criteria can be used to perform an unmanned aerial vehicles classification [8]. Some of them, such as size, MTOW (Maximum Takeoff Weight), and range will be considered in Section 4, where UAV flight regulation is analyzed. In this section, the classification has been made considering the wing type and autonomy level that could be the most relevant criteria in agricultural missions.

\subsection{According to the Type of Wing}

Two main sets can be found: rotary and fix wings. Hybrid UAVs that combine previous wings systems have been obviated since no applications in agricultural missions have been found.

The first group is made up of helicopters and multi-rotor (popularly known as drones). The airflow is created by several rotors that generate the appropriate trust for lifting. Their 
main advantage is the capacity to perform hovering flights, which is relevant to aerial photography since it allows increasing the capture time for the cameras and therefore compensate poor light scenarios. Moreover, they show great performance at low velocities and allow low altitude flights with minimum risk.

Multi-rotors have become more popular due to their mechanical simplicity in comparison to helicopters, which rely on a much more sophisticated plate control mechanism. Thus, the multi-rotor flight is controlled just by varying the speed of several direct current (DC) motors, without any mechanical moving mechanism, in contrast to helicopters. Moreover, the fall in price of brushless motors, which require no maintenance, as well as their electronic controllers, has made them an affordable solution for multiple tasks in civil applications. Due to this, a relevant number of drone manufacturers have emerged in the market providing a wide variety of systems.

The main shortcoming of commercial drones is their lower payload capacity in comparison with helicopters. Nevertheless, drone manufacturers have increased the number of rotors from 4 to 6 or even 8 so as to reduce this gap and currently drones with a maximum payload capability of $22 \mathrm{~kg}$ [9] are available on the market. Not only does payload capacity increase with the number of rotors, but there is also an improvement in safety, since the aircraft usually is able to fly in deteriorate mode when one or even more rotors is under failure, allowing for landing in a safe manner.

On the other hand, fixed wing aircraft, such as planes, require creating airflow to lift by displacing their aerodynamic surfaces (wings and ailerons) at high speeds. Therefore, they are not able to perform static flights. Since the speed cannot be reduced in the same manner as rotary wings, they usually require higher altitude to perform safe flights. In addition to this, the maneuverability shown by rotary wings (e.g., immediate rotations on vertical axis) is a great advantage over those with fixed wings.

Although the maximum range that a fixed wing aircraft can reach is higher than rotary wings, due to legal regulations for flying UAVs, it does not become a real advantage in most of the cases, even though for the most part they also exhibit a higher payload capacity.

In summary, the analysis carried out in this survey shows that rotary wings aircrafts are mostly preferred for agricultural tasks than those with fixed wings.

\subsection{According to the Autonomy Level}

Other criteria for classifying the UAVs apart from their aerodynamic principles could be their autonomy level. Thus, the drones could be classified into teleoperated when the pilot provides references to each actuator of the aircraft so as to control it in the same manner an onboard pilot would do. This lower level of autonomy is mainly used for recreational or hobby purposes, since it is the most adequate at performing acrobatic maneuvers.

A second level of autonomy is shown by the tele-commanded vehicles. In this case, the aircraft relies on an automatic controller on board that is in charge of maintaining a stable flight. The ground operator is able to provide velocity and orientation commands to the onboard controller so as to define the vehicle trajectory. They are mostly used in non-structured environments or when the flight plan cannot be decided in a priori mission definition, i.e., when the trajectory depends on the findings. A typical example of this are the visual inspections by drones, in which the drone is mainly used as a remote camera for operators to evaluate the unknown state of an infrastructure and the trajectory of the vehicle depends on the human decision made in real time.

The highest level of autonomy corresponds to autonomous vehicles, which are able to perform some kind of flight plan without human intervention. Most of the commercial systems that rely on GPS on board allow defining a ordered list of 3D (longitude, latitude and height) points called waypoints that the vehicle has to follow [10-13]. In the case of drones, a fourth coordinate, called heading (typically the deviation with respect to the North) can be also provided. Moreover, some actions can usually be triggered when the vehicle reaches a desired waypoint, such as taking a picture. 
Autonomous takeoff and landing [14] involve a higher level of autonomy since cleared areas are required, therefore in most of cases these operations are supervised by the drone operator.

The complexity of the missions that can be defined by commercial UAVs is usually not very advanced. However, a manual selection of waypoints over a map is usually available. So as to increase this level of complexity, some manufacturers provide their own software development kits (SDK) [15,16] or even applications [17-19]. Specialized service companies as well as research centers have developed more advanced applications for specific missions. Thus, a survey on coverage path planning techniques with unmanned aerial vehicles can be found in [20].

The most commonly reported missions involving UAVs could be classified according to the following types:

- Waypoint trajectory. A flight plan is created taking pictures and videos at the waypoints.

- Mapping mission. An area is covered and a 2D map or image is created by using mosaicking procedures.

- Oblique mission: Several flights are performed with different points of view in order to create a 3D model of the target.

- Corridor mission: The flight plan is along a target (river, aerial power line, railway line, among others).

When huge dimension fields have to be covered in an agricultural mission, using a fleet of vehicles can be a solution so as to reduce the total time required to complete the mission, and therefore, obtain more homogeneous images due to possible changes in light [21-26].

Due to this, the activity of research centers is currently focused in providing fleets of UAVs with a high level of autonomy [27,28], which involves advanced ground control systems that reduce the number of operators required to manage the fleet by using automatic supervision processes [29].

\section{Unmanned Aerial Systems Used in Agriculture}

This section summarizes the main features of the UAS components used in agriculture.

\subsection{Aerial Vehicles}

Thus, some manufacturers have designed their own customized drones for agricultural tasks. In fact, Yamaha remote piloted helicopters have been operating from 1991 and nowadays continue developing newer products only focused on agriculture. Although they do not sell the helicopters, they provide them with a full service that includes maintenance and qualified pilots.

Other companies, such as DJI [30], have developed customized models for crop protecting against insects or weeds by carrying out the integration of specific sensors such as multispectral, high precision RTK GPS, and high-resolution cameras. As another example, Parrot Bluegrass Fields [31] is a complete drone solution, drone + multispectral sensor + processing software, ready to fly and suitable for the entire crop analysis workflow. Parrot Bluegrass Fields provides farmers with information to maximize their yield and improve the quality of their crops.

Apart from commercial products, in this work, an exhaustive investigation in the literature focused on UAV mission in agriculture has been carried out. Table 1 shows the most relevant features of some drones reported as been applied in agricultural tasks.

Considering UAVs, there is always a trade-off between endurance (maximum time of fight) and payload. Thus, if endurance increases (by adding more powerful batteries or a higher capacity fuel tank), the payload decreases due to the increment in weight. Due to this, the values of payload and endurance shown in Table 1 should be considered as a mere reference, since these values are strongly interrelated. A selection of commercial drones included in this table is shown Figure 3. 
Table 1. Main characteristics of some UAVs used in agriculture.

\begin{tabular}{|c|c|c|c|c|}
\hline Type & UAV & $\begin{array}{l}\text { Payload } \\
\text { (kg) }\end{array}$ & $\begin{array}{l}\text { Endurance } \\
\text { (min) }\end{array}$ & Dimensions (m) \\
\hline \multirow{6}{*}{8 rotors } & MK Okto XL 2 & 4 & 46 & $0.95 \times 0.73 \times 0.45$ \\
\hline & Okto-XL & 2.5 & 25 & $1.045 \times 0.45$ \\
\hline & DJI Agras MG-1 & 10 & - & $1640 \times 1471 \times 482$ \\
\hline & Spreading Wings S1000 & $6-11$ & 15 & $1.1 \times 1.1 \times 0.38$ \\
\hline & ARF-MikroKopter & 2.5 & 28 & $0.73 \times 0.73 \times 0.36$ \\
\hline & AT8 UAV & 2 & 30 & $1.2 \times 1.2 \times 0.4$ \\
\hline \multirow{6}{*}{6 rotors } & EM6-800 & 1.2 & 25 & $0.8 \times 0.8 \times 0.32$ \\
\hline & Matrice 100/S1000 & 1 & 40 & 0.65 \\
\hline & DJI M600 & 4.5 & 16 & $1.6 \times 1.5 \times 0.7$ \\
\hline & Hexacopter P-Y6/A2500_WH & 3 & 21 & $1 \times 0.45$ \\
\hline & HEXA-PRO ${ }^{\mathrm{TM}} \mathrm{UAV}$ & 2 & 40 & 0.85 \\
\hline & AIR-200 & 3 & 40 & 2.2 \\
\hline \multirow{7}{*}{4 rotors } & Parrot AR/2.0 & - & 12 & $0.52 \times 0.51$ \\
\hline & Parrot Anafi & - & 25 & $224 \times 67 \times 65$ \\
\hline & Phantom 2/3 Pro/4 Pro & 0.3 & 30 & 0.35 \\
\hline & DJI Mavic Pro/inspire 1/inspire 2 & 0.2 & 21 & $0.29 \times 0.28 \times 0.11$ \\
\hline & Jifei P20 UAV & 12 & 20 & $1.8 \times 1.8 \times 0.47$ \\
\hline & MD4-100/1000 & 1.2 & 45 & 1.03 \\
\hline & 3DR Iris/Solo & 0.4 & 22 & $0.4 \times 0.63 \times 0.15$ \\
\hline \multirow{3}{*}{ Helicopters } & Yamaha Fazer R & 32 & 25 & $3.66 \times 770 \times 1.078$ \\
\hline & Rotomotion SR200 & 20 & 240 & 2.5 \\
\hline & SKeldar V200 & 40 & 300 & 4.6 \\
\hline \multirow{7}{*}{ Fixed wing } & Gatewing X100 & 0.2 & 15 & $1 \times 0.6 \times 0.1$ \\
\hline & zangão uav & 1.1 & 60 & 1.95 \\
\hline & Trinity F90+ & - & 90 & 2.394 \\
\hline & eBee SQ/Plus & 0.3 & 59 & 1.1 \\
\hline & M23 UAV & 14.6 & 25 & $3.1 \times 2.9 \times 1.4$ \\
\hline & Tuffwing Mapper & 2 & 40 & $1.2 \times 0.6 \times 0.2$ \\
\hline & Airborne XT & 200 & 3900 & $9.9 \times 3.6 \times 1.9$ \\
\hline
\end{tabular}

\subsection{Sensors}

The reduction in weight and consumption of newer equipment and measurement instruments has made it possible to improve the UAV sensorial systems and therefore to expand their field of applications.

Although information regarding sensors (when available) will be provided in Section 3, where relevant examples of reported agricultural missions that use UAV have been classified and presented, a classification of the most common sensors has been performed in this work. Thus, they can be mainly clustered in several sets: RGB (visible spectrum) sensors, multi-spectral, and hyperspectral cameras. The main difference between multispectral and hyperspectral imaging is the number of wavebands being imaged and how narrow the bands are. Multispectral imagery generally refers to 3 to 10 discrete "broader" bands, whereas hyperspectral imagery relies on much narrower bands.

Moreover, laser systems, thermal cameras, and multi-scanner devices are also used, as Table 2 shows.

Although most of the applications eveloped are focused on data acquisition, a lower percentage focused on the agricultural treatment application, such as fertilizers, fumigation or irrigation have been also reported. Therefore, UAVs can be equipped with tanks and end effectors as nozzles, used for treatment application, among these, the $3 \mathrm{~W}-1000 \mathrm{Y}$ boom sprayer pressure nozzles.

Finally, additional sensors are used to measure environmental variables in crops, such as temperature, humidity, gas emissions, within which we can mention RHT03 temperature, MG811 $\mathrm{CO}_{2}$ concentration, Gas nano, and humidity sensors. 


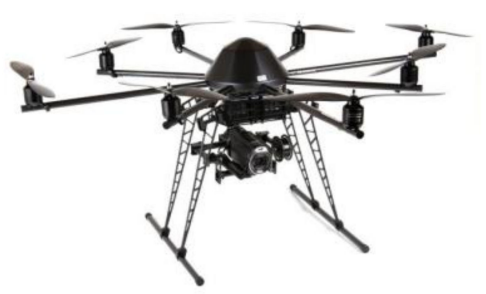

(a)

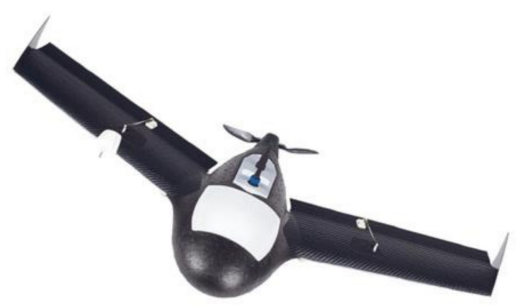

(c)

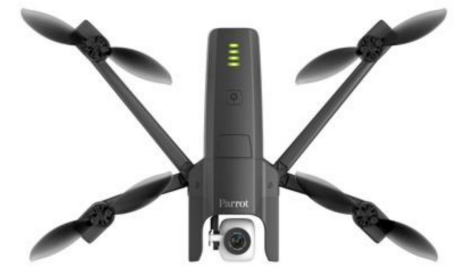

(b)

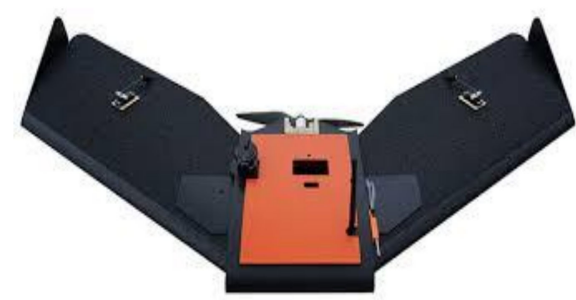

(d)

Figure 3. Commercial drones used for precision agriculture purposes. (a) Eight-rotors MK Okto XL 2, by HiSystems GmbH/Mikrokopter.de (b) quad-rotor Parrot Anafi, (c) Gatewing X100, and (d) Tuffwing Mapper. Permission obtained.

Table 2. Sensors commonly used in UAV for agricultural tasks.

\begin{tabular}{|c|c|c|}
\hline Sensor Type & Brand & Main Features \\
\hline \multirow{5}{*}{ RGB } & Canon Powershot SX540 & $20.3 \mathrm{MP} 442 \mathrm{~g}$ \\
\hline & Olympus PEN E-PM1 & $12 \mathrm{MP} 216 \mathrm{~g}$ \\
\hline & Sony Nex-7/ILCE & $24.2 \mathrm{MP} 416 \mathrm{~g}$ \\
\hline & Ricoh GR3 & $16.9 \mathrm{MP} 257 \mathrm{~g}$ \\
\hline & Sony $\alpha 7 \mathrm{r}$ & $36.4 \mathrm{MP} 407 \mathrm{~g}$ \\
\hline \multirow{23}{*}{ Multi spectral } & \multirow{3}{*}{ MicaSense RedEdge } & R G B Red Edge NIR \\
\hline & & $1280 \times 960$ \\
\hline & & $230 \mathrm{~g}$ \\
\hline & \multirow{3}{*}{ MCA camera } & $4,6,12$ bands (user-selectable) \\
\hline & & $1280 \times 1024$ \\
\hline & & $497 \mathrm{~g}$ (per camera) \\
\hline & \multirow{3}{*}{ Mini MCA } & $4,6,12$ bands (user-selectable) \\
\hline & & $1280 \times 1024$ \\
\hline & & $600,700,1300 \mathrm{~g}$ \\
\hline & \multirow{4}{*}{ Micro MCA } & $4,6,12$ bands (user-selectable) \\
\hline & & $1280 \times 1024$ \\
\hline & & $497,530,1000 \mathrm{~g}$ \\
\hline & & R G Red Edge NIR \\
\hline & \multirow{2}{*}{ Parrot Sequoia } & $2 \mathrm{MP}$ \\
\hline & & $72 \mathrm{~g}$ (Includes $16 \mathrm{Mp}$ RGB Camera) \\
\hline & \multirow{3}{*}{ InGaAs } & Infrared \\
\hline & & $640 \times 512$ \\
\hline & & R G NIR \\
\hline & \multirow[t]{3}{*}{ Tetracam ADC lite } & $2048 \times 1536$ pixels \\
\hline & & $200 \mathrm{~g}$ \\
\hline & & R G NIR \\
\hline & \multirow[t]{2}{*}{ Tetracam ADC micro } & $2048 \times 1536$ pixels \\
\hline & & $90 \mathrm{~g}$ \\
\hline
\end{tabular}


Table 2. Cont.

\begin{tabular}{|c|c|c|}
\hline Sensor Type & Brand & Main Features \\
\hline \multirow[t]{2}{*}{ Laser } & Velodyne VLP-16 & $\begin{array}{c}\text { range: } 100 \mathrm{~m} \\
\text { FOV: } 360 \text { deg Horizontal } \pm 15^{\circ} \text { Vert } \\
\text { Accuracy: } 3 \mathrm{~cm} \\
830 \mathrm{~g}\end{array}$ \\
\hline & $\begin{array}{c}\text { Hokuyo UTM-30LX } \\
\text { Nikon Forestry Pro II } \\
\text { Ragefinder/Hypsometerm }\end{array}$ & $\begin{array}{c}\text { Range: } 30 \mathrm{~m} \text { FOV: } 270 \mathrm{deg} \\
\text { Angular res: } 0.25 \mathrm{deg} \\
\text { Accuracy: } 50 \mathrm{~mm} \\
210 \mathrm{~g} \\
\text { Range: } 7 \mathrm{~m}-1600 \mathrm{~m} \text { FOV: } 7.5 \text { degrees } \\
170 \mathrm{~g}\end{array}$ \\
\hline \multirow{10}{*}{ Thermal } & & $640 \times 512$ \\
\hline & DJI Zenmuse XT & $7.5-13.5 \mu \mathrm{m}$ \\
\hline & & $\begin{array}{c}\text { Weight: } 270 \mathrm{~g} \\
640 \times 512\end{array}$ \\
\hline & Xenics Bobcat 640 GigE SWIR/vSWIR & $500-1700 \mu \mathrm{m}$ \\
\hline & & $285 \mathrm{~g}$ \\
\hline & & $384 \times 288$ \\
\hline & Thermoteknix MicroCAM Integrator & $17 \mu \mathrm{m}$ \\
\hline & & $60 \mathrm{~g}$ \\
\hline & FLIR Vue Pro R & $640 \times 512$ \\
\hline & FLIK vue Pro $\mathrm{K}$ & $113 \mathrm{~g}$ \\
\hline MultiScanner & RapidSCAN CS-45 & $670,730,780 \mathrm{~nm}$ \\
\hline
\end{tabular}

\section{Agronomic Applications of the UAV}

According to the existence or not of a physical interaction with crops, two main groups of precision agriculture tasks involving UAVs can be observed. Thus, most applications exhibiting some kind of physical interaction could be classified into the "crop spraying" cluster (i.e., dusting, irrigation, or fertilization), although some examples of soil sampling with UAV have been also reported [32]. Applications that do not require physical interaction will be clustered under the "remote sensing" topic in this work.

On the other hand, a marginal number of applications such as goods transportation with UAVs could also be considered, since they correspond with farm management tasks. Nevertheless, they have been not considered properly agronomic tasks in this study.

\subsection{Remote Sensing}

Remote sensing applications in agriculture deal with non-contact procedures to obtain information on the state of the fields. Two main groups of applications may, in turn, be observed into this cluster: the ones that aim to perform environmental control by registering physical parameters such as humidity, temperature, or different gas concentrations, which will be classified under the environmental monitoring in this work, and those that are directly focused on the crops.

Continuous crop monitoring could be considered an essential aspect of precision agriculture and requires the registration of sensor data over long periods of time. Thus, agricultural fields can be monitored by using cameras and sensors attached to UAVs.

Most of the remote sensing techniques applied to agriculture are based on the interaction of electromagnetic radiation with soil and crops. Thus, remote sensing involves the measurement of reflected radiation instead of transmitted or absorbed ones. The amount of radiation reflected from plants is inversely related to radiation absorbed by plant pigments and varies with the wavelength of incident radiation [33].

In addition to reflectance, plant leaves emit energy by fluorescence [34] and thermal emission [35], which is typically applied to water stress detection in crops. These techniques are based on measuring the emission of radiation in response to the temperature of the leaf and canopy, which varies with air temperature and the rate of evapotranspiration. 
Depending on the size of the field to be observed, it is common that a single image capture of the sensor is not able to cover all the terrain, and therefore, a geo-referred mosaic by integrating all the images is required. In those cases, a more complex flight plan should be performed, typically by defining waypoints where the sensor acquisition has to be done [36]. High overlap values near to 60 or even $80 \%$ between subsequent images or between tracks are usually applied [28,37].

This section shows relevant applications of UAV in remote sensing tasks by categorizing them according to their goal in:

\subsubsection{Nutrients Evaluation and Health Assessment}

Integrating multispectral aerial data on soil and crop with geophysical data allows adapting the application of nutrients to each zone of the field. Thus, soil-available nutrients monitoring is essential for crop growth assessment and allows performing appropriate variable-rate fertilization to avoid unnecessary damage to sustainable production capacity.

With this aim, a new method for soil available nutrients estimation with high accuracy is proposed in [38], where algorithms that improve the resolution of time-series satellite data using UAV flying over maize fields were applied in China. Moreover, in [39] LiDAR and multispectral imaging sensors on board of an a DJI M600 Pro multirotor UAV is used to monitor sugarcane fields with variable nitrogen fertilization inputs in Australia. The application provides with crop growth information in terms of height, density and vegetation indices and estimates a set of models to predict biomass at fine scale. Furthermore, the application also estimates a model to predict contemporaneous leaf nitrogen content by using multispectral images.

The Effective $\mathrm{N}$ (Nitrogen) fertilizer management can either avoid $\mathrm{N}$ stress or provide timely and accurate detection of in-season nitrogen stress for remedies. According to [40], traditional $\mathrm{N}$ trial experiments to evaluate different management practices require waiting until harvest, not allowing a tracking of when and how $\mathrm{N}$ stress happens. However, remote sensing technology from UAVs offers new opportunities for in-season evaluation of $\mathrm{N}$ status and detection of $\mathrm{N}$ stress for crops. Thus, an application for monitoring rice leaf nitrogen status in Chine is presented in [41] by using a RapidSCAN CS-45 with three wavebands, including red, red-edge, and near-infrared regions onboard a multi-rotor UAV Spreading Wings S1000+ by DJI endowed with a high precision RTK (Real Time Kinematics) GNSS (Global Navigation Satellite System).

Although changes in the visual appearance of the yields and/or the fields stand for challenges to conventional image registration methods, a method for registering images of agricultural fields taken by an UAV over the crop season, as well as a complete pipeline for processing temporally aligned 3D point clouds of the field by taking advantage of the inherent geometry of the crop are presented in [42].

Similar techniques can be applied to crops such as winter wheat. Thus, in [43] two different payloads UAVs were used to perform an evaluation of crop performance based on high-resolution images. A small DJI Phantom 4 Pro was in charge of obtaining RGB images, whereas a DJI Matrice 100 platform specifically designed was in charge of carrying the multispectral MicaSense RedEdge-M camera and downwelling light sensor. A high precision $(3 \mathrm{~cm})$ RTK GPS was used to establish the ground control point targets required for geo-referring.

An eBee Plus, a fixed wing aircraft by SenseFly, has also been successfully used to evaluate the breeding process of Central European winter wheat [44] by using the Monteith Moss equation, which calculates grain yield as the product of incident photosynthetically active radiation, fraction of intercepted radiation, radiation use efficiency, and harvest index. The trial was carried out in Germany with a spatial resolution of 80-squared mm per pixel and using an overlapping of $80 \%$ between consecutive passes. Reflection data were provided by a multispectral Sequoia camera, which records simultaneously in four wavebands: green, red, red edge, and near-infrared. 
Applications of multispectral information over other kinds of crops such as tomatoes and vineyards are also found [45]. A hexacopter ESAFLY A2500_WH, by SAL Engineering and a Tetracam ADC Micro camera were used.

Not only growth monitoring, but also health assessment applications, can be found in the literature. Thus, stripe rust, which is an important disease of wheat, is monitored by multispectral imaginary from UAV in [46], where a five-bands RedEdge camera onboard DJI S1000 was used to capture images with a resolution of 1-1.5 cm/pixels by flying $20 \mathrm{~m}$ height eight times during the growth season.

Xylella fastidiosa, which is a bacterial plant pathogen affecting a wide variety of plants (over 350), has been detected in olive trees by using high-resolution visible and multispectral images acquired by a Italdron $4 \mathrm{HSE}$ EVO, a medium size multirotor endowed with a 3D gimbal, a compact five band multispectral camera (MicaSense RedEdge-M), a high-resolution thermal camera (FLIR Vue Pro 640), and a high-resolution visible camera (Sony $\alpha 7 \mathrm{r}$ ) during flights with a height of tens of meters [47].

The high spatial resolution that can be obtained when flying drones endowed with high resolution cameras at low altitude is demonstrated in [48], where computer vision models demonstrate being able to recognize northern leaf blight disease in the field by detecting millimetric lesions in plants.

\subsubsection{Water Stress Analysis}

Precision agriculture aims at optimizing crop production by adapting management actions such as watering to the needs of the soil. For this, a reliable and extensive description of soil and crop conditions is required.

A remarkable comparative carried out in Italy between free thermal images provided by Landsat- 8 satellite and the very high resolution ones obtained by one-hundred-metersheight flights of an UAV is presented in [37]. The study makes use of a four-rotor UAV model Matrice 210 made by DJI that relies on a dual-gimbal configuration to handle the simultaneous use of two sensors' payloads. The thermal camera was a DJI Zenmuse XT providing $640 \times 512$ pixels images with a focal length of $13 \mathrm{~mm}$.

The study was focused on evaluating water stress conditions and optimization of irrigation management practices, especially on wetlands affected by saline soils and saltwater capillary rise. Thus, UAV data was applied to verify the quality of the land surface temperature and canopy estimated from the satellite at every passage. Although the comparison showed discrepancies (i.e., satellite derived temperatures were usually lower than UAV measurements), both methods turned out to be useful to estimate water stress index.

Numerous applications have been proposed including water stress assessment at field by thermal imagery, but the drifts during data acquisition have to be corrected. A comprehensive methodology for radiometric correction of UAV thermal images to obtain multispectral ortho mosaics for assessment of tree response to water stress is presented in [49].

A comparison of the effectiveness of hyperspectral and multispectral data in detecting citrus nitrogen and water stresses can be found in [50]. The multispectral and/or hyperspectral data are used for determining water band index (WBI) as well as other vegetation indices.

Other works are focused on estimating water stress in vineyards at canopy scale by using methods based on shortwave infrared data obtained from an UAV [51]. In this case, a single-band Xenics Bobcat 640 GigE video camera, which provides a 640 by 512 pixels signal, a multispectral Parrot Sequoia sensor, with a resolution of 1280 by 960 pixels in four available bands and a sunshine sensor to adjust for different irradiance conditions were required. The experiments were carried out in Greece and the results show that spanning from no-stress to severe canopy stress levels assessment was reached.

Other agricultural cases, such as the evaluation golf courses irrigation needs from UAV video images is described in [52]. 


\subsubsection{Yield and Biomass Estimate}

Yield estimates by using aerial images from UAVs over main cereals in the world, such as maize, rice, wheat [53], barley [54] or Sorghum can be found in the literature.

Thus, an estimate over wheat crops is presented in [55] by using images from a FabryPerot interferometer-based spectral camera onboard of an autonomous helicopter created on Mikado Logo 600 with a $5 \mathrm{~kg}$ payload capacity. The flight height required was $140 \mathrm{~m}$. Another estimation of wheat plants density at the emergence stage is presented in [56]. In this work, high-resolution images taken by using a Sony ILCE $\alpha 5100 \mathrm{~L}$ RGB (24Mpixels and $60 \mathrm{~mm}$ focal length lens) onboard a hexacopter developed by Atechsys were used. This system provides a ground resolution between $0.20 \mathrm{~mm}$ to $0.45 \mathrm{~mm}$. Flight plans were carried out in order to obtain a $59-77 \%$ overlap between images. In contrast with other applications that rely on cameras pointing downwards, a $45^{\circ}$ zenith angle was used to reduce the effect of the wind created by the rotors and to maximize the cross section viewed of the plants.

A high-throughput method for estimation of biomass in rice is presented in [57]. The near-infrared imagery is provided by a Tetracam ADC-lite multispectral camera onboard a four-rotor drone during flights carried out at different scales of the crop.

Machine learning and computer vision applied to high-resolution images acquired by using a DJI Phantom 4 Pro and a 4K RGB camera provide an accurate and efficient high-throughput plant phenotyping over Sorghum crops in [58].

Apart from cereals, grass or cotton applications are also found. Thus, in [59], a quadrotor DJI Phantom 2 endowed with a Canon Powershot S110 camera was used as a low-cost aerial imagery system to evaluate the potential of sward height metrics derived from the aerial images at the Rengen Grassland Experiment in Germany.

A work that explores the potential of using visible-band images from a DJI Phantom 2 Vision+ multirotor, which relies on a 14-Mpixel fisheye-lens camera, to assess cotton growth in Texas (USA) is presented in [60].

Monitoring the growth dynamics in orchards is also of high relevance to optimize farm management. Accordingly, a method of extracting features from trees with an irregular crown shape such as peach trees is presented in [61]. The trials were carried out in Japan, by using a digital camera mounted looking downwards on a DJI inspire 1 and inspire 2 UAV during $30 \mathrm{~m}$ height and $80 \%$ of overlap. Other trees types been also analyzed. Thus, in [62] a $2 \mathrm{~m}$ wingspan plane $\mathrm{mX-SIGHT}$ was used over olive trees in Spain to assess their crown parameters by using a Panasonic Lumix DMC-GF1 RGB camera, which was modified for color infrared (CIR) detection by removing the internal infrared filter. In this manner, the camera provides images of $4000 \times 3000$ pixels with results approximately in seven $\mathrm{cm} /$ pixel resolution at an approximate altitude of $300 \mathrm{~m}$.

The feasibility of a system to efficiently classify and select olive tree genotypes according to four architectural parameters: tree height, crown diameter, projected crown area, and canopy volume by using a 24 Mpixel Sony ILCE-6000 camera, onboard a MD4-1000 by Microdrones is presented in [63], whereas the analysis of the effect of pruning by using the same UAV but using a 12Mpixel Olympus PEN E-PM camera is presented in [64]. Applications focused on Norway spruce and Scots pine [65] and Mediterranean riparian forest [66] can also be found.

\subsubsection{Soil Monitoring}

In this regard, monitoring erosion of the soil is also relevant, since it can cause a progressive degradation of hillslopes, especially in steep-slope agricultural landscapes. Thus, in [67] an evaluation of spatial erosion patterns was carried out in different vineyard establishments in Italy: dry-stone wall terraces, earth bank terraces, and vertical cultivation. The high-resolution of the data provided turns out to be useful when integrated into GIS-based erosion models. Two models of drones by DJI: Mavic Pro and Phantom 4 Pro were used to this purpose with cameras between 12.3 mega pixels and 20 mega pixels of resolution during flights at $30-40-50 \mathrm{~m}$ of height. 
A fixed-wing aircraft type Sirius I (MAVinci) equipped with a digital Panasonic camera is employed in [68] to fly varying extents and flying heights in order to create Digital Terrain Models and ortho-image mosaics with very high resolution on a sub-decimeter level.

\subsubsection{Weeds Detection}

Accurate weed maps of the crop-field are required to optimize the application of herbicides. Nevertheless, detecting weeds when crop and weed plants are at early phenological stages and exhibit spectral and appearance similarities is a challenging objective that can only be overcome by using high-spatial-resolution images with pixel size smaller than $0.05 \mathrm{~m}[69]$.

A complete analysis that evaluates the efficacy and limitations of remote images taken from UAV for early detection of weed seedlings can be found in [70]. According to this study, a right selection of the spatial resolution and date of flight are crucial for being successful. Consequently, the low altitude that drones are able to maintain and their high availability in comparison to satellite images or commercial manned flights allow selecting the date of study without hard requirements.

On the other hand, using color-infrared or visible-light images depends on the size of the plants and therefore, the time elapsed from seeding. Some authors apply those techniques on maize fields [71] and wheat [72], with flights in a range of 30 to $100 \mathrm{~m}$ of altitude by using a Microdrones MD4-1000 quadrotor.

Another example of the adequacy of light-weight UAV such as the Phantom 4 by DJI to capture images for weeds detection can be found in [73], where those techniques are applied to crops such as sugar beets.

Fixed wing unmanned aerial vehicles are also used in weed detection. Thus, a procedure based on neural networks and the fusion of low resolution multispectral and high resolution RGB images is introduced in [74] so as to detect Gramineae weed in rice fields at Colombia, with plants at 50 days after emergence (DAE) by flights carried out at altitudes from 60 to $70 \mathrm{~m}$ with a fixed wing aircraft.

Artificial intelligence techniques have been extensively used to detect weeds by using aerial images obtained from UAV. Thus, in [75] a fully automatic learning method using convolutional neuronal networks (CNNs) with an unsupervised training dataset collection is presented so as to perform weed detection from UAV images.

On the other hand, few works make use of a fleet of drones to carry out, in a coordinate manner, the aerial image acquisitions for agricultural purposes so far. Although this solution shows relevant advantages such as a higher uniformity in light conditions due to the reduction in time required to complete the mission, some safety and coordination problems arise. Thus, only when vast fields have to be covered, is using a fleet of vehicles worthwhile from an economical point of view, since not only multiple vehicles endowed with sensors and cameras are required, but also multiple drone operators according to most of legislations.

A representative example of this approach can be found in the RHEA project [28] where a fleet of two AR-200 drones by AirRobot were able to perform $30 \mathrm{~min}$ missions with a payload of $1.5 \mathrm{~kg}$ due to the near infrared camera and the gimbal system for image stabilization and camera orientation. Probably the most relevant contribution of this work related to the use of an UAV fleet is the task planification system, which was based on a previous one developed for single UAV area coverage [76] where safety issues turned out to be of the highest relevance. This planification system was integrated into the whole fleet (aerial and ground vehicles) mission planner.

\subsubsection{Environmental Monitoring}

UAVs have probes to be able to act as mobile elements in wireless sensor networks to gathering data [77-79]. In this regard, in [80] paper presents a hierarchical structure based on the collaboration between unmanned aerial vehicles and federated wireless sensor networks (WSNs) for crop monitoring in precision agriculture. 
Not only open-air, but also indoor agricultural uses of UAVs can be found in the literature. Thus, in [81] the design, construction and validation of a mobile sensory platform for greenhouse monitoring in Almeria (Spain) is presented. The complete system consists of a sensory system onboard a light quadrotor (Parrot AR.Drone 2.0). The system provides temperature, humidity, luminosity, and $\mathrm{CO}_{2}$ concentration information and creates maps of these variables so as to allow climate control and failures detection (e.g., a break in a plastic cover). $\mathrm{CH}_{4}$ and $\mathrm{CO}$ are also monitored in [82] by using a DJI Inspire Pro UAV and an active AirCore.

\subsection{Aerial Spraying}

As mentioned in Section 2, most probably the first UAV application to agriculture was a fumigation system with a Yamaha R-max helicopter. Newer models of Yamaha continue performing tasks in Japan and the USA (typically on vineyards). Recently, a relevant number of cases of uses of unmanned aerial vehicles (UAV) for pesticide application have been reported against a wide range of crops with promising results in East Asian countries such as Japan, South Korea and China.

According to [83], China owned 1400 agricultural fixed-wing aircrafts, more than 60 helicopters, and over 10,000 UAVs in 2017. Thus, the area of agricultural and forest pest and disease control and fertilization using fixed-wing aircraft and helicopters reached two million hectares.

Nevertheless, UAV aerial spraying ability is not limited to crop protection, but it is also applied to crop fertilization. During these processes, the distribution and deposition of droplets or fog fields could directly influence the effectiveness and efficiency of spray. Although off-target and insufficient amounts of droplet deposition density during the spraying operation has been a major concern for UAV aerial spraying, advances in technology allow us to perform aerial spraying in rice cultivation [84]. In this study, an evaluation of the optimal parameters, such as the speed of a customized eight-rotor UAV and the spraying rate on the droplet deposition density are analyzed. During the field trials, an organic liquid fertilizer was sprayed at the different flying speeds $(2,4,6 \mathrm{~m} / \mathrm{s})$, two meters above the rice canopy and varying the spraying rate. Other approaches are focused on variable spray systems [85] where a M23 UAV (Shenzhen Hi-tech New Agriculture Technologies Co, Ltd., Shenzhen, China) was used to apply the treatment by using a miniature diaphragm pump (PLD-2201) and a pressure nozzle (110-015 by Lechler). Moreover, some studies [86] are focused in performing a more precise efficiency assessment method, based on the reflection of LIDAR.

\section{UAV Flying Regulation for Agricultural Tasks}

Although each country may have different specific laws and regulations, there are some of them that are common all over the world. Thus, most of the countries have some kind of drone regulation distinguished between recreational and commercial activities. Recreational flights have significantly less restrictions than commercial flights.

Thus, the most common maximum height for drones is 300-400 ft. or $120 \mathrm{~m}$, considering this as a safety height so as to avoid interferences with other aircrafts. It is also recommended not to fly over people or near crowds, not allowing the drone to get out of eyesight, and only flight in the daylight.

The main aspects of regulation in Europe define the technical and operational requirements for the drones not only aiming to reduce the risk to people and other aircrafts but also privacy, security and data protection issues. Under these premises, EASA (the European Union Aviation Safety Agency) developed in 2019 the "Easy Access Rules for Unmanned Aircraft Systems" (Regulations (EU) 2019/947 and (EU) 2019/945) and established three categories for the UAS operations with different safety requirements: 
- Open category shall not be subject to any prior operational authorization, nor to an operational declaration by the UAS operator.

- Specific category, which requires an authorization by the competent authority prior to the operation that includes an operational risk assessment report, except for certain standard scenarios where a declaration by the operator is sufficient or when the operator holds a light UAS operator certificate (LUC) with the appropriate privileges.

- Certified, which requires the certification of the UAS, a licensed remote pilot and an operator approved by the competent authority.

The regulation framework for operations in 'certified' category is currently under development.

Most of the agriculture operations with UAV could be classified under the "open" category provided that a maximum takeoff mass vehicle is less than $25 \mathrm{~kg}$. Moreover, the unmanned aircraft has to be maintained within $120 \mathrm{~m}$ from the closest point of the surface of the earth, except when overflying an obstacle.

Nevertheless, there is a more restrictive constraint, since the remote pilot has to keep the unmanned aircraft in continuous visual line of sight operation (VLOS), allowing the remote pilot to control the flight path of the unmanned aircraft, keeping a safe distance from people, other aircrafts, and obstacles for the purpose of avoiding collisions while ensuring that it is not flying over assemblies of people.

In general, agricultural flights do not involve risks for people, since a very reduced number of people are usually present in fields, however maintaining the VLOS restriction could be a barrier in huge field crops, where several flights may be required to cover the whole extension. Another possible solution that the legislation allows is to make use of follow-me mode (where the UAV operator is onboard of a mobile vehicle during the flight).

It is worth noting that during flight, the unmanned aircraft will neither carry dangerous goods nor drop any material.

The new European drone rules will come into force on 31 December 2020. Then, drones do not need registering (unless they are certified by EASA). Nevertheless, drone operators must register with the Civil Aviation Authority (CAA) of their EU country of residence to obtain a registration number (unique for all Europe) that should be exhibited on a sticker on the drone and has to be uploaded onto the 'Drone's remote identification system'. The registration will be valid for a period defined by the corresponding national CAA after which it needs to be renewed.

However, operators do not need to register if their drones weigh less than $250 \mathrm{~g}$ and have no camera or other sensors able to detect personal data. If the UAV is under the category of 'toy' (directive 2009/48/EC), it is free of register although it relies on a camera, provided that it weighs less than $250 \mathrm{~g}$.

On the other hand, according to the FAA, flying a drone is legal in the U.S., but the activity has to be compliant with some drone regulations. Thus, when flying drones due to non-recreational purposes, the drone operator must hold a Remote Pilot Certificate issued by the FAA to fly commercially and the UAV should be registered with the FAA. The maximum takeoff weight is 55 pounds. Only flights into Class $G$ airspace are allowed, keeping the UAV within visual line-of-sight. The flight has to be carried out at or below 400 feet in daylight or civil twilight and with a speed limit of $100 \mathrm{mph}$. Flights over people are banned. The operator can only fly from a moving vehicle in a sparsely populated area.

Excluding the weight requirement and the requirement to fly in Class $\mathrm{G}$ airspace, the above restrictions can be waived if reliant on special waivers or approvals from the FAA.

A complete list of regulations applicable at most of the countries in the world can be found at [87].

\section{Conclusions}

As previously stated, there are many advantages of using UAVs in agriculture: 
- UAVs require neither a dedicated airport nor a navigation station, and usually can land on the edge of cultivated lands. This also reduces the no-load flight rate in spraying tasks.

- High maneuverability: Although this feature is intrinsic to rotary wing aircrafts, the fixed-wing ones also show short turning radius, high rate of climbing and a good performance during super low flights.

- They are suitable for working in rough terrain and small plots with high efficiency.

- They exhibit lower operational costs due to their reduced flight crew requirements, low labor intensity, and simple maintenance in comparison to traditional manned aircrafts.

For all these reasons, there is an increment in the use of drones in agriculture. Moreover, this work proves that the affordable prize and vantage point that UAVs enable make them a valuable tool to be used in precision agriculture. Thus, scientific works exhibit multiple worldwide successful applications over most main crops, such as wheat, maize, rice, olives, fruit trees, etc., as Section 3 describes.

In the same manner, those applications focused on key precision agriculture tasks underline that the current state of technology sensors (mainly multi-spectral, RGB cameras, and laser systems) provides with light and low consumption, but high-resolution devices make the UAV systems an adequate instrument for many agricultural purposes. Although rotary-wing aircrafts are mostly used, fixed-wings also show relevant contributions. In any case, the reduced weight required for most of the remote sensing activities allows them to fulfill the legal requirements in most of the countries around the world at a reasonable cost. Specifically, according to the analysis carried out, some conclusions may be obtained:

Considering nutrients evaluation and health assessment missions, multi-spectral or lighter RGB cameras are usually required. These sensors require medium payload capacity drones (between 1 or $2 \mathrm{~kg}$ ) and multi-rotor aircrafts are usually selected.

In water stress detection missions, infrared/thermal cameras are usually selected. Nevertheless, some procedures also require multi-spectral cameras (higher payload), although as in previous cases, medium payload multi-rotors are capable of carrying the sensors onboard.

Yield and biomass estimate, soil monitoring, and weed detection missions usually require RGB or NIR cameras. Depending on the optical requirements, very light cameras can be used, therefore low payload capability quadrotors (low cost) can be used. The weight of the camera lens is noteworthy and directly affects the area that a single image covers. Therefore, using lighter cameras can lead to lower altitude flights and more images are required to cover the whole field. For environmental monitoring missions, low-cost drones with light sensors are usually applied.

Without a doubt, the higher payload capacity (higher dimensions and cost) drones are required for aerial spraying missions. Drones with a payload from 10 to $50 \mathrm{~kg}$ are available for these tasks.

The review of the commercial systems reveals that drones' manufacturers are aware of the relevance of agriculture in UAV markets, which has been verified by an observation of their customized services focused on agriculture. Nevertheless, it is expected that a high number of service-provider companies will appear in a short time to offer high technology services to farmers by using UAVs.

For all these reasons, the analysis carried out foresees a rosy future for UAVs in agriculture. Moreover, the new 5G radio standard technology will allow performing high resolution $(4 \mathrm{~K})$ streaming in real time and incorporating smart cameras that include newer artificial intelligence features. One challenge behind severe regulations on the beyond visual line of sight (BVLOS) flights is that the pilot must always be able to intervene in case something unexpected happens. This can only be done if there is a permanent and reliable connection from the pilot to the drone that $5 \mathrm{G}$ could provide. 
Author Contributions: Conceptualization, J.d.C., A.B., C.C.U.; methodology, J.d.C., A.B., C.C.U.; formal analysis, J.d.C., A.B., C.C.U.; investigation, J.d.C., C.C.U., J.d.L.R.; writing-original draft preparation, J.d.C., C.C.U.; writing-review and editing, J.d.C.; visualization, J.d.C.; supervision, A.B.; funding acquisition, J.d.C., A.B. All authors have read and agreed to the published version of the manuscript.

Funding: The research leading to these results has received funding from RoboCity2030-DIH-CM, Madrid Robotics Digital Innovation Hub, S2018/NMT-4331, funded by "Programas de Actividades I+D en la Comunidad de Madrid" and co-funded by Structural Funds of the EU and from the project "Robot para el cultivo en hileras y reciclaje de residuos para la producción intensiva de vegetables y eficiencia energética" PCI2018-093074, funded by Proyectos de I+D+I, Programación Conjunta Internacional, programa estatal de $\mathrm{I}+\mathrm{D}+\mathrm{I}$ orientada a los Retos de la Sociedad. Agencia Estatal de Investigación.

Acknowledgments: This work was accomplished thanks to the important support of: ERAnet CORE Organic 294 Cofound-Sureveg Project, PCI2018-093074, AEI (Agencia Estatal de Investigación), Centro de Automática y Robótica (CSIC-UPM).

Conflicts of Interest: The authors declare no conflict of interest.

\section{References}

1. Association for Unmanned Vehicle Systems International-AUVSI. Available online: www.auvsi.org (accessed on 11 October 2020).

2. Commercial Drone Market Size, Share E Trends Analysis Report By Application (Filming E Photography, Inspection E Maintenance), by Product (Fixed-Wing, Rotary Blade Hybrid), by End Use, and Segment Forecasts, 2019-2025; Grand View Research: San Francisco, CA, USA, 2019.

3. Johnson, A.A. McCook Field 1917-1927; Landfall Press: Dayton, OH, USA, 2002; pp. 190-191; ISBN 0-913428-84-1.

4. Colwell, R.N. Determining the prevalence of certain cereal crop diseases by means of aerial photography. Hilgardia 1956, 26, 223-286. [CrossRef]

5. Sugeno, M.; Hirano, I.; Kotsu, S. Development of an intelligent unmanned helicopter. In Proceedings of the 1995 IEEE International Conference on Fuzzy Systems, Yokohama, Japan, 14-20 March 1995; Volume 5, pp. 33-34.

6. Yamaha Motors. Available online: https://www.yamahamotorsports.com/motorsports/pages/precision-agriculture-rmax (accessed on 26 September 2020).

7. Gilmore, J. The autonomous helicopter system. In Proceedings of the Society of Photo-Optical Instrumentation Engineers, Arlington, VA, USA, 14 June 1984; Volume 485, pp. 146-152.

8. Korchenko, A.; Illyash, O. The generalized classification of Unmanned Air Vehicles. In Proceedings of the 2013 IEEE 2nd International Conference Actual Problems of Unmanned Air Vehicles Developments Proceedings (APUAVD), Kiev, Ukraine, 15-17 October 2013; pp. 28-34.

9. Rc Wing. Available online: https:/ / www.hobby-wing.com/agricultural-drones.html (accessed on 30 December 2020).

10. Santana, L.; Brandão, A.; Sarcinelli-Filho, M. Outdoor waypoint navigation with the AR.Drone quadrotor. In Proceedings of the International Conference on Unmanned Aircraft Systems (ICUAS), Denver, CO, USA, 9-12 June 2015; pp. 303-311.

11. Capello, E.; Guglieri, G.; Quagliotti, F. A Waypoint-Based Guidance Algorithm for mini UAVs. In Proceedings of the 2nd IFAC Workshop on Research, Education and Development of Unmanned Aerial Systems, Compiegne, France, 20-22 November 2013.

12. DJI. Ace Waypoints. Available online: https://www.dji.com/es/ace-waypoint (accessed on 10 September 2020).

13. Parrot. Parrot Flight Plan. Available online: https://support.parrot.com/us/support/products/parrot-bebop-2-fpv/flight-plan (accessed on 10 September 2020).

14. Gautam, A.; Sujit, P.; Saripalli, S. A survey of autonomous landing techniques for UAVs. In Proceedings of the Conference: 2014 International Conference on Unmanned Aircraft Systems (ICUAS), Orlando, FL, USA, 27-30 May 2014.

15. PARROT. Bebop Drone for Developers. Available online: https://developer.parrot.com/docs/bebop/ (accessed on 10 October 2020).

16. DJI. DJI Developer SDK. Available online: https:// developer.dji.com/?site=ag\&from=footer (accessed on 10 October 2020).

17. DJI. Terra Utility. Available online: https://www.dji.com/es/dji-terra (accessed on 10 October 2020).

18. Microcopter. Microcopter Tool. Available online: https://wiki.mikrokopter.de/en/MikroKopterTool (accessed on 10 October 2020).

19. SenseFly. eMotion. Available online: https://www.sensefly.com/software/emotion/ (accessed on 10 October 2020).

20. Cabreira, T.; Brisolara, L.; Ferreira, P., Jr. Survey on Coverage Path Planning with Unmanned Aerial Vehicles. Drones $2019,3,4$. [CrossRef]

21. Ju, H.; Il Son, H. Multiple UAV Systems for Agricultural Applications: Control, Implementation, and Evaluation. Electronics 2018, 7, 162. [CrossRef] 
22. Elmokadem, T. Distributed Coverage Control of Quadrotor Multi-UAV Systems for Precision Agricultur. IFAC Pap. 2019, 52, 251-256. [CrossRef]

23. Skobelev, P.; Budaev, D.; Gusev, N.; Voschuk, G. Designing Multi-agent Swarm of UAV for Precise Agriculture. In Proceedings of the Highlights of Practical Applications of Agents, Multi-Agent Systems, and Complexity: The PAAMS Collection. PAAMS 2018. Communications in Computer and Information Science, Toledo, Spain, 20-22 June 2018; Springer: Cham, Switzerland, 2018; Volume 887.

24. $\mathrm{Hu}, \mathrm{J} . ;$ Yang, J. Application of distributed auction to multi-uav task assignment in agriculture. IJPAA 2018, 1. [CrossRef]

25. Ju, C.; Son, H. Discrete Event Systems based Modeling for Agricultural Multiple Unmanned Aerial Vehicles: Automata Theory Approach. In Proceedings of the 18th International Conference on Control, Automation and Systems (ICCAS), Pyeong Chang, Korea, 17-20 October 2018; pp. 258-260.

26. Albani, D.; IJsselmuiden, J.; Haken, R.; Triann, V. Monitoring and mapping with robot swarms for agricultural applications. In Proceedings of the 2017 14th IEEE International Conference on Advanced Video and Signal Based Surveillance (AVSS), Lecce, Italy, 29 August-1 September 2017; pp. 1-6.

27. Barrientos, A.; Colorado, J.; del Cerro, J.; Martinez, A.; Rossi, C.; Sanz, D.; Valente, J. Aerial Remote Sensing in Agriculture: A Practical Approach to Area Coverage and Path Planning for Fleets of Mini Aerial Robots. J. Field Robot. 2011, 28, 667-689. [CrossRef]

28. Gonzalez-de-Santoos, P.; Ribeiro, A.; Fernandez-Quintanilla, C.; Lopez-Granados, F.; Brandstoetter, M.; Tomic, S.; Debilde, B. Fleets of robots for environmentally-safe pest control in agriculture. Precis. Agric. 2017, 18, 574-614. [CrossRef]

29. Roldan, J.J.; del Cerro, J.; Barrientos, A. A proposal of methodology for multi-UAV mission modeling. In Proceedings of the Mediterranean Conference on Control Automation, Torremolinos, Spain, 16-19 June 2015.

30. DJI. Drones for Agriculture. Available online: https://ag.dji.com/es?site=brandsite\&from=nav (accessed on 10 October 2020).

31. Parrot. Parrot Bluegrass Fields. Available online: https://atyges.es/tienda/en/parrot-bluegrass-fields/ (accessed on 10 October 2020).

32. Huuskonen, J.; Oksanen, T. Soil sampling with drones and augmented reality in precision agriculture. Comput. Electron. Agric. 2018, 154, 25-35. [CrossRef]

33. Mulla, D. Twenty five years of remote sensing in precision agriculture: Key advances and remaining knowledge gaps. Biosyst. Eng. Spec. Issue Sens. Agric. Rev. 2013, 114, 358-371. [CrossRef]

34. McMurtrey, J.; Corp, L.; Kim, M.; Chappelle, E.; Daughtry, C.; DiBenedetto, J. Fluorescence techniques in agricultural applications. In Proceedings of the Volume 10301, Optics in Agriculture: 1990-2000: A Critical Review, Boston, MA, USA, 28 March 2001; p. 1030104. [CrossRef]

35. Ishimwe, R.; Abutaleb, K.; Ahmed, F. Applications of Thermal Imaging in Agriculture-A Review. Adv. Remote Sens. 2014, 3, 128. [CrossRef]

36. Valente, J.; Barrientos, A.; Del Cerro, J.; Sanz, D. A waypoint-based mission planner for a farmland coverage with an aerial robot-a precision farming tool. In Proceedings of the 8th European Conference on Precision Agriculture (ECPA'11), Prague, Czech Republic, 11-14 July 2011; pp. 427-436.

37. Masina, M.; Lambertini, A.; Daprà, I.; Mandanici, E.; Lamberti, A. Remote Sensing Analysis of Surface Temperature from Heterogeneous Data in a Maize Field and Related Water Stress. Remote Sens. 2020, 12, 2506. [CrossRef]

38. Meng, J.; Cheng, Z. Improving the estimation of soil-available nutrients at the sub-field scale using time-series UAV observations. Remote Sens. Lett. 2020, 11, 739-747. [CrossRef]

39. Shendryk, Y.; Sofonia, J.; Garrardc1, R.; Rista, Y.; Skocajd, D.; Thorburna, P. Fine-scale prediction of biomass and leaf nitrogen content in sugarcane using UAV LiDAR and multispectral imaging. Int. J. Appl. Earth Obs. Geoinf. 2020, 92, 102177. [CrossRef]

40. Cai, Y.; Guan, K.; Nafziger, E.; Chowdhary, G.; Peng, B.; Jin, Z.; Wang, S. Detecting In-Season Crop Nitrogen Stress of Corn for Field Trials Using UAV- and CubeSat-Based Multispectral Sensing. IEEE J. Sel. Top. Appl. Earth Obs. Remote Sens. 2019, 12, 5153-5166. [CrossRef]

41. Songyang, L.; Ding, X.; Kuang, Q.; Ata-UI-Karim, S.; Cheng, T.; Liu, X.; Cao, W. Total views article has an altmetric score of 1 View Article Impact Suggest a Research Topic > SHARE ON 000 New original research article. Front. Plant Sci. 2018. [CrossRef]

42. Chebrolu, N.; Läbe, T.; Stachniss, C. Robust Long-Term Registration of UAV Images of Crop Fields for Precision Agriculture. IEEE Robot. Autom. Lett. 2018, 3, 3097-3104. [CrossRef]

43. Heidarian Dehkordi, R.; Burgeon, V.; Fouche, J.; Placencia Gomez, E.; Cornelis, J.-T.; Nguyen, F.; Meersmans, J. Using UAV Collected RGB and Multispectral Images to Evaluate Winter Wheat Performance across a Site Characterized by Century-Old Biochar Patches in Belgium. Remote Sens. 2020, 12, 2504. [CrossRef]

44. Rose, T.; Kage, H. The Contribution of Functional Traits to the Breeding Progress of Central-European Winter Wheat Under Differing Crop Management Intensities. Front Plant Sci. 2019, 6, 1521. [CrossRef]

45. Candiago, S.; Remondino, F.; De Giglio, M.; Dubbini, M.; Gattelli, M. Evaluating Multispectral Images and Vegetation Indices for Precision Farming Applications from UAV Images. Remote Sens. 2015, 7, 4026-4047. [CrossRef]

46. Su, J.; Liu, C.; Hu, X.; Xu, X.; Guo, L.; Chen, W.-H. Spatio-temporal monitoring of wheat yellow rust using UAV multispectral imagery. Comput. Electron. Agric. 2019, 167, 105035. [CrossRef]

47. Di Nisio, A.; Adamo, F.; Acciani, G.; Attivissimo, F. Fast Detection of Olive Trees Affected by Xylella Fastidiosa from UAVs Using Multispectral Imaging. Sensors 2020, 20, 4915. [CrossRef] [PubMed] 
48. Wiesner-Hanks, T.; Wu, H.; Stewart, E.; DeChant, C.; Kaczmar, N.; Lipson, H.; Nelson, R.J. Millimeter-Levl Plant Disease Detection From Aerial photographs via Deep Learning and Crowdsourced Data. Front. Plant Sci. 2019, 12, 1550. [CrossRef] [PubMed]

49. Gómez-Candón, D.V. Field phenotyping of water stress at tree scale by UAV-sensed imagery: New insights for thermal acquisition and calibration. Precis. Agric. 2016, 17, 786-800. [CrossRef]

50. Bhandari, S.; Raheja, A.; Chaichi, M.; Pham, F.; Sherman, T.; Dohlen, M.; Khan, S. Comparing the effectiveness of hyperspectral and multispectral data in detecting citrus nitrogen and water stresses. In Proceedings of the Volume 11008, Autonomous Air and Ground Sensing Systems for Agricultural Optimization and Phenotyping IV, Baltimore, MD, USA, 15-16 April 2019.

51. Kandylakis, Z.; Falagas, A.; Karakizi, C.; Karantzalos, K. Water Stress Estimation in Vineyards from Aerial SWIR and Multispectral UAV Data. Remote Sens. 2020, 12, 2499. [CrossRef]

52. Perea-Moreno, A.-J.; Aguilera-Ureña, M.-J.; Meroño-De Larriva, J.-E.; Manzano-Agugliaro, F. Assessment of the Potential of UAV Video Image Analysis for Planning Irrigation Needs of Golf Courses. Water 2016, 8, 584. [CrossRef]

53. Schirrmann, M.; Giebel, A.; Gleiniger, F.; Pflanz, M.; Lentschke, J.; Dammer, K.-H. Monitoring Agronomic Parameters of Winter Wheat Crops with Low-Cost UAV Imagery. Remote Sens. 2016, 8, 706. [CrossRef]

54. Roosjen, P.; Suomalainen, J.; Bartholomeus, H.; Clevers, J. Hyperspectral Reflectance Anisotropy Measurements Using a Pushbroom Spectrometer on an Unmanned Aerial Vehicle-Results for Barley, Winter Wheat, and Potato. Remote Sens. 2016, 8, 909. [CrossRef]

55. Honkavaara, E.; Saari, H.; Kaivosoja, J.; Pölönen, I.; Hakala, T.; Litkey, P.; Pesonen, L. Processing and Assessment of Spectrometric, Stereoscopic Imagery Collected Using a Lightweight UAV Spectral Camera for Precision Agriculture. Remote Sens. 2013, 5, 5006-5039. [CrossRef]

56. Jin, X.; Liu, S.; Baret, F.; Hemerlé, M.; Comar, A. Estimates of plant density of wheat crops at emergence from very low altitude UAV imagery. Remote Sens. Environ. 2017, 198, 105-114. [CrossRef]

57. Devia, C.A.; Rojas, J.P.; Martinez, C.; Mondragon, I.F.; Patino, D.; Rebolledo, M.; Colorado, J. High-Throughput Biomass Estimation in Rice Crops Using UAV Multispectral Imagery. J. Intell. Robot. Syst. 2019, 96, 573-589. [CrossRef]

58. Lin, Z.; Guo, W. Sorghum Panicle Detection and Counting Using Unmanned Aerial System Images and Deep Learning. Front. Plant Sci. 2020. [CrossRef] [PubMed]

59. Lussem, U.; Schellberg, J.; Bareth, G. Monitoring Forage Mass with Low-Cost UAV Data: Case Study at the Rengen Grassland Experiment. PFG J. Photogramm. Remote Sens. Geoinf. Sci. 2020. [CrossRef]

60. Chu, T.; Chen, R.; Landivar, J.; Maeda, M.; Yang, C.; Starek, M.J. Cotton growth modeling and assessment using unmanned aircraft system visual-band imagery. J. Appl. Remote Sens. 2016, 10, 036018. [CrossRef]

61. Mu, Y.F. Characterization of peach tree crown by using high-resolution images from an unmanned aerial vehicle. Hortic. Res. 2018, 5, 74. [CrossRef]

62. Díaz-Varela, R.A.; De la Rosa, R.; León, L.; Zarco-Tejada, P.J. High-Resolution Airborne UAV Imagery to Assess Olive Tree Crown Parameters Using 3D Photo Reconstruction: Application in Breeding Trials. Remote Sens. 2015, 7, 4213-4232. [CrossRef]

63. Rallo, P.; de Castro, A.; López-Granadosb, F.; Morales-Silleroa, A.; Torres-Sánchezb, J.; Jiménez, M.; PazSuáreza, M. Exploring UAV-imagery to support genotype selection in olive breeding programs. Sci. Hortic. 2020, 273, 109615. [CrossRef]

64. Jiménez-Brenes, F.L.-G. Quantifying pruning impacts on olive tree architecture and annual canopy growth by using UAV-based 3D modelling. Plant Methods 2017, 13, 55. [CrossRef]

65. Panagiotidis, D.; Abdollahnejad, A.; Surový, P.; Chiteculo, V. Determining tree height and crown diameter from high-resolution UAV imagery. Int. J. Remote Sens. 2017, 38, 2392-2410. [CrossRef]

66. Dunford, R.; Michel, K.; Gagnage, M.; Piégay, H.; Trémelo, M.-L. Potential and constraints of Unmanned Aerial Vehicle technology for the characterization of Mediterranean riparian forest. Int. J. Remote Sens. 2009, 30, 4915-4935. [CrossRef]

67. Pijl, A.; Reuterb, L.; Quarellaa, E.; Vogelb, T.; Tarollia, P. GIS-based soil erosion modelling under various steep-slope vineyard practices. CATENA 2020, 193, 104604. [CrossRef]

68. D'Oleire-Oltmanns Sebastian, M.; Peter, K.; Johannes, B.R. Unmanned Aerial Vehicle (UAV) for Monitoring Soil Erosion in Morocco. Remote Sens. 2012, 4, 3390-3416. [CrossRef]

69. López-Granados, F.; Torres-Sánchez, J.; Serrano-Pérez, A.; de Castro, A.I.; Mesas-Carrascosa, F.J.; Pena, J.M. Early season weed mapping in sunflower using UAV technology: Variability of herbicide treatment maps against weed thresholds. Precis. Agric. 2016, 17, 183-199. [CrossRef]

70. Torres, S.; Torres-Sánchez, J.; Serrano-Pérez, A.; De Castro, A.; López-Granados, F. Quantifying Efficacy and Limits of Unmanned Aerial Vehicle (UAV) Technology for Weed Seedling Detection as Affected by Sensor Resolution. Sensors 2015, 15, 5609-5626.

71. Torres-Sanchez, J.; lopez-Granados, F.; De Castro, A.; Peña-Barragán, J. Configuration and Specifications of an Unmanned Aerial Vehicle (UAV) for Early Site Specific Weed Management. PLoS ONE 2013, 6, e58210. [CrossRef] [PubMed]

72. Gómez-Candón, D.; De Castro, A.; López-Granados, F. Assessing the accuracy of mosaics from unmanned aerial vehicle (UAV) imagery for precision agriculture purposes in wheat. Precis. Agric. Vol. 2014, 15, 44-56. [CrossRef]

73. Lottes, P.; Khanna, R.; Pfeifer, J.; Siegwart, R.; Stachniss, C. UAV-based crop and weed classification for smart farming. In Proceedings of the 2017 IEEE International Conference on Robotics and Automation (ICRA), Singapore, 29 May-3 June 2017; IEEE: Singapore, 2017.

74. Barrero, O.; Perdomo, S. RGB and multispectral UAV image fusion for Gramineae weed detection in rice fields. Precis. Agric. Vol. 2018, 19, 809-822. [CrossRef] 
75. Bah, M.; Hafiane, A.; Canals, R. Deep Learning with Unsupervised Data Labeling for Weed Detection in Line Crops in UAV Images. Remote Sens. 2018, 10, 1690. [CrossRef]

76. Valente, J.; Sanz, D.; Del Cerro, J.; Barrientos, A.; De Frutos, M. Near-optimal coverage trajectories for image mosaicking using a mini quad-rotor over irregular-shaped field. Precis. Agric. 2013, 14, 115-132. [CrossRef]

77. Valente, J.; Sanz, D.; Barrientos, A.; Cerro, J.; Ribeiro, A.; Rossi, C. An air-ground wireless sensor network for crop monitoring. Sensors 2011, 11, 6088-6108. [CrossRef]

78. Di Gennaro, S.; Matesea, A.; Gioli, B.; Toscano, P.; Zaldei, A.; Palliotti, A.; Genesio, L. Multisensor approach to assess vineyard thermal dynamics combining high resolution Unmanned Aerial Vehicle (UAV) remote sensing and wireless sensor network (WSN) proximal sensing. Sci. Hortic. 2017, 221, 83-87. [CrossRef]

79. Polo, J.; Hornero, G.; Duijneveld, C.; García, A.; Casas, O. Design of a low-cost Wireless Sensor Network with UAV mobile node for agricultural applications. Comput. Electron. Agric. 2015, 119, 19-32. [CrossRef]

80. Popescu, D.; Stoican, F.; Stamatescu, G.; Ichim, L.; Dragana, C. Advanced UAV-WSN System for Intelligent Monitoring in Precision Agriculture. Sensors 2020, 20, 817. [CrossRef] [PubMed]

81. Roldán, J.; Joossen, G.; Sanz, D.; Del Cerro, J.; Barrientos, A. Mini-UAV Based Sensory System for Measuring Environmental Variables in Greenhouses. Sensors 2015, 15, 3334-3350. [CrossRef] [PubMed]

82. Andersen, T.; Scheeren, B.; Peters, W.; Chen, H. A UAV-based active AirCore system for measurements of greenhouse gases. Atmos. Meas. Tech. 2018, 11, 2683-2699. [CrossRef]

83. Xiongkui, H.; Bonds, J.; Herbst, A.; Langenakens, J. Recent development of unmanned aerial vehicle for plant protection in East Asia. Int. J. Agric. Biol. Eng. 2017, 10, 18-30. [CrossRef]

84. Kharim, M.; Wayayokab, A.; Shariffab, A.; FikriAbdullahab, A.; MohdHusinab, E. Droplet deposition density of organic liquid fertilizer at low altitude UAV aerial spraying in rice cultivation. Comput. Electron. Agric. 2019, 167, 105045. [CrossRef]

85. Wen, S.; Zhang, Q.; Deng, J.; Lan, Y.; Yin, X.; Shan, J. Design and Experiment of a Variable Spray System for Unmanned Aerial Vehicles Based on PID and PWM Control. Appl. Sci. 2018, 8, 2482. [CrossRef]

86. Yongjun, Z.; Shenghui, Y.; Lan, Y.; Hoffmann, C.; Chunjiang, Z.; Liping, C.; Yu, T. A novel detection method of spray droplet distribution based on LIDARs. Int. J. Agric. Biol. Eng. 2017, 10, 54-65. [CrossRef]

87. Master List of Drone Laws (Organized by State \& Country). Available online: https://uavcoach.com/drone-laws/ (accessed on 3 October 2020). 